\title{
The Struggles of the First Generation on Women Stereotypes in the Joy Luck Club Novel
}

\author{
Riana Permatasari ${ }^{1}$, Muhammad Fajar ${ }^{2}$ \\ English Literature Department, Faculty of Languages and Communication Science, Universitas Islam Sultan \\ Agung, Semarang, Indonesia \\ 1permatasari@unissula. ac.id
}

\begin{abstract}
Women stereotypes are deeply embedded in a patriarchal society. Women and men are regarded for having different roles leading to the limitations faced by the women. This study analyzes the struggles of the first generation of Chinese immigrant women as reflected in The Joy Luck Club Novel in dealing with the negative woman stereotypes. The data were collected from the novel by reading the novel, identifying, and classifying the data based on the research problem. After that, the data were analyzed using the underlying theory of the study that is the struggles related to Chinese woman stereotypes. Based on the findings, there are three ways done by the first generation of Chinese immigrant women in order to face the stereotypes including being active, breaking the silence, and storytelling. By doing these three struggles, they can reach their happiness, freedom, and betterment.
\end{abstract}

Keywords: Women stereotype, Chinese society, Struggles on women stereotypes

\section{Introduction}

In countries that uphold a patriarchal belief men and women have different role in the societies. Their roles are influenced by the beliefs, norms, as well as values living in the societies. One of the countries upholding the patriarchal belief is Chinese society. In China, men and women are illustrated by the relationship between Qian and Kun regarded as the heaven and the earth (Peng, 2014) The men are regarded as Qian and Women as Kun. This belief lead to the perspective that men have superior roles compared to women.

Similarly Rhim (n.d) explains that the Chinese cosmology, Yin and Yang, contributes to the roles of men and women in Chinese society. Yang is the male principle representing the positive and superior forces, stood for heaven, sun, height, strength, and action, whereas Yin is the female element representing negative and inferior counterparts of the male, signified earth, mood, depth, darkness, and passivity (Fajar, 2018). These beliefs lead men and women for having different roles where men's job is to earn living whereas women's job is to stay at home for taking care the family as indicated in proverb saying "Men plough and women weave," (Lee, 2015).

Those beliefs make women face stereotypes in their lives. The stereotypes that the Chinese women face in their lives including dealing with domesticity, being passive and submissive. Further, these stereotypes lead them to face oppressions formed by the society. In order to face the oppressions, they have to struggle in three ways according to Tangapiwut (2012), including being active, breaking the silence and storytelling.

There are many literary studies have discussed about the women stereotypes as well as the struggles on it. However, they tend to talk the struggles done by the second generation that have been experienced different cultures in host countries. Thus, it raised the question on how the first generation struggles on the women stereotypes that they face. The Joy Luck Club novel has explored the issue of women stereotypes and their struggles in facing it either for the first and second 
generation. The novel narrates four Chinese women, An-Mei Hsu, Lindo Jong, Suyuan Woo, and Ying Ying S. Clair, experiencing negative stereotypes in their society that limit them in developing their personal abilities, careers and choices in their lives. They do many struggles in facing the stereotypes that can be learned by other women in dealing with stereotypes.

In brief, based on the explanation above, this study is intended to analyze how the first generation struggles to face the women stereotypes depicted in The Joy Luck Club Novel.

\section{Literature Review: Women Stereotypes in Chinese Society}

According to Dovidio, Hewstone, and Glick (n.d), stereotype is a term introduced by W. Lippman in 1992 who defines stereotype as the typical picture that people have when thinking of a particular social group. Similarly, Snyder (2008) also asserts that a stereotype is a typical picture about a social group that can be positive or negative, accurate or inaccurate, justified or unjustified. Thus, the negative, inaccurate and unjustified stereotypes can cause misleading conception toward a certain group.

Discussing about stereotypes, the notion of gender stereotypes is an inevitable issue to discuss in which men and women are regarded to have different roles in society. Gender stereotypes are defined as a belief about the psychological traits, characteristics, as well as activities suitable for men or women (Brannon, n.d). Gender stereotypes further can influence the conceptualization of men and women in a culture as the stereotypes are associated with the roles and behaviors of men and women. It is sometimes different with the behaviors that men and women perform in their daily lives but this belief is powerful in judging of self and other. For example, a woman is considered as a good wife if she does domestic works and does not work outside the house. This opinion is not an absolute fact as there are many factors representing a good wife, but if she does not follow the stereotype then she will not be considered as a good wife.

The reason of why gender stereotypes become very influential and powerful comes from the historical notion in a culture or a country. Lewin (1984 cited in Brannon n.d), explains that the gender stereotypes existing nowadays reflect the belief appeared in $19^{\text {th }}$ century known as Victorian Era. In the Victorian era, the industrial revolution changes the lives of the Europe people; from men and women used to work together shifted to men work outside to earn living and women stay at home to do household and take care of the children (Brannon, n.d). This change exists and develops to gender stereotype influencing how people think about women and men.

In addition, in the West women are considered intellectually inferior to men and a major source of temptation and evil as stated by Peng (2014). Similarly, in China, a patriarchal belief that is strongly embedded in the society is also influenced by its historical notion. In China women and men have their own different stereotypes when men have the dominant roles and women have subordinate roles as the patriarchal ideology highlights biological differences between men and women (Brannon, n.d). This further causes stereotypes that women are weak, indecisive, submissive, passive and require protection from men whereas men are considered as strong, active and self-confident (Tangapiwut, 2012).

Moreover, Chinese society also believes that men are defined as Qian or the heaven and women as Kun or the Earth (Peng, 2014). This belief picturizes that women have subordinate roles to men for most of their lives. Similarly, the Chinese cosmology states that the world is composed by two complementary elements name Yang representing men and Yin representing women (Rhim, n.d). The male principles cover positive and superior forces, stood for heaven, sun, height, strength, and action; whereas the female principles include negative and inferior counterparts of the male, signified earth, mood, depth, darkness, and passivity (Rhim, n.d). Thus, it is clear that since the early time in Chinese culture, women are regarded inferior to men.

In addition, Ling (1990 quoted in Peng 2014, 150) asserts that in Chinese culture, women should follow the Three Obedience and the Four Virtues as stated in the following quotation 
The Three Obedience enjoined a woman to obey her father before marriage, her husband after marriage and her eldest son after her husband's death. The Four Virtues decreed that she be chaste; her conversation courteous and not gossipy, her department graceful but not extravagant; her leisure spent in perfecting needlework and tapestry for beautifying the home.

From the quotation above, it is indicated that the women have to be obedient towards men and the society starting from their childhood to their adulthood life. Three Obedience means that women should obey their father before marriage, their husband after marriage and their eldest son after their husband's death. It indicates that throughout their lives, they do not have rights in choosing as they have to obey whatever their father, husband, as well as eldest son says. Chinese women are not allowed to express their opinion because it is not a proper thing to do and regarded as a selfish desire (Tangapiwut, 2012). Thus, it is clear that in Chinese society, a woman should be passive and submissive to be regarded as an ideal woman. In terms of The Four Virtues, women are expected to be chaste, courteous, graceful. In addition, women are also supposed to do needlework to beautify the home that shows that they should dealing with domestic works. By obeying the Three Obedience and the Four Virtues they will be regarded as good women.

Moreover, some Chinese proverbs have separated the sphere of men and women; the women are in the domestic sphere whereas the men are out of the house. One of the proverbs is Men plough and women weave (Lee, 2015). This proverb is deeply embedded in the society and influences the way of thinking of its people in which they regard men to work outside the house and women work inside the house to take care of the family.

The women stereotypes have an effect towards women in which limit them in developing their abilities and get some oppressions. In order to against the negative stereotypes, there are three ways that women can take to face the stereotypes including being active, breaking the silence, and storytelling (Tangapiwut, 2012). First thing to do to against the stereotypes is being active that demands women to play an active role in getting rid of the negative effects of the stereotypes. Tangapiwut (2012) argues that being active also means that women should change their perspective towards the negative stereotypes so that they can change other people's perspective. Second thing is breaking the silence. Based on He-Feng (2007 quoted in Tangapiwut, 2012), breaking the silence can be done generally, internally, and externally. Generally, breaking the silence is shown by thinking critically, speaking out their needs and having others know their presence. Internally, the women are anxious and worried about sexual discrimination and realize that the problems can only be eradicated through knowledge and understanding. Breaking the silence is also done externally that the factor resulting from changing social conditions in the contemporary worlds such as feminist movement. They can also move to other country where they can find a better life. Third way to fight the negative stereotypes are storytelling that makes the women and their generation break away from the negative effect of women stereotypes (Gallego, 1999). By storytelling, the women and their generation will be able to achieve reconciliation so the harmfulness of women stereotypes can be prevented. By doing these three ways, the women can deal with the oppressions and the negative stereotypes.

\section{Method}

This study belongs to qualitative study as it aims at understanding aspects of social life that generate words as data for analysis (Patton \& Cochran, 2002). The data of this study were in the form of sentences both in monologues as well as dialogues. The data were collected through three steps including: (1) reading the novel thoroughly to get the deep understanding of the whole content of the novel, (2) identifying the data that reflected the problem discussed in the study, and (3) classifying the data based on the problem discussed in this study into a table consisting of three columns including the monologues/dialogues taken, form of the data, and where the data were found. After gathering the data, the data were analyzed using the theory underlying this study which is the 
struggles related to Chinese women stereotypes. The selected data were analyzed with the references of why the data could answer the research problem.

\section{4. $\quad$ Findings}

In The Joy Luck Club novel, there are four Chinese immigrant women narrated in the novel namely Lindo Jong, An-Mei Hsu, Suyuan Woo, and Ying-ying St. Clair. They belong to the first generation Chinese immigrant women who face negative stereotypes in their lives. These stereotypes lead them to many kinds of oppressions. In dealing with the negative stereotypes, the first Chinese immigrant women do many struggles to against the stereotypes including being active, breaking silence, and storytelling. The followings are details of each point.

\section{Being Active}

Tangapiwut (2012) asserts that in order to change the society's perspective about the women stereotypes, women should change their attitude towards themselves in which they have to believe that they can make a better day for their future and they do active role in the society. In the novel, being active is shown by Lindo, An-mei and Suyuan.

Based on the data gathered from the novel. Lindo is narrated as a woman who has to do forced marriage arranged by her parents. As a Chinese woman who has to be submissive, she finally follows her parents' wish but she still keeps believing that she will fight the oppressions she gets someday. It is indicated in the following quotation stating "I made promises to myself: I would always remember my parents' wish, but I would never forget myself," (Tan, 1990: 58). This quotation is taken when she was about to marry her husband. It indicates that she will do struggles to fight the oppressions she gets and will show who she is. Changing her own perspective towards the stereotypes belongs to being active as stated by Tangapiwut (2012) that a woman should change her perspective before changing other people's perspective.

Lindo's active role continues during her marriage; her husband stereotypes her as weak, passive, submissive, and domestic. She tries to run away from her forced marriage as shown in the following quotation.

The day I started to think about how I would escape this marriage...I made the Huangs think it was their idea to get rid of me, that they would be the ones to say the marriage contract was not valid. I thought about my plan for many days. I observed everyone around me, the thoughts they showed in their faces and then I was ready (Tan, 1990: 63).

From the above quotation, Lindo is trying to end her forced marriage as she does not want to live under the oppression for the whole life time. She starts thinking of how she can escape from her marriage without being blamed by the Huangs. She uses every single opportunity to influence the Huangs that she is not good for the family until she successfully ends her marriage and gets divorced from her husband.

Similarly, Suyuan also tries to do active role to fight the negative stereotypes by creating mahjong club where she gathers other Chinese women to share their thoughts and story. They face the same oppressions as Chinese women and Suyuan hopes that by sharing the stories they can help each other and change their attitudes and perspective about themselves. Suyuan says "Each week we could forget past wrongs done to us. We weren't allowed to think a bad thought," (Tan, 1990: 25). The act of gathering the women who have same problems with her signals that she is trying to be active in dealing with the negative stereotypes. She tries to change the other women's perspective so that they can fights the stereotypes together.

Likewise, being active as the way dealing with the negative stereotypes is shown by An-Mei. In the story, An-Mei lives with Wu Tsing who makes her mother as his fourth wife. In the house, she and her mother always get bad acts from Wu Tsing as well as his second wife. They stereotype them 
as passive and weak. One day when she feels very angry with the act of the Second Wife, she says "And on that day, I showed Second Wife the fake pearl necklace she had given me and crushed it under my foot. And on that day, I learned to shout," (Tan, 1990: 240). Crushing the pearl necklace and shouting are to show Second Wife that she is not weak and passive. She shows her that she is the source of the misery for her and her mother. She wants to approve that she can fight the negative stereotypes.

\section{Breaking the Silence}

Breaking the silence can be done generally, internally, and externally. In general, breaking the silence is in the shape of thinking critically; speaking out their needs and having other knows their presence. The act of thinking critically is shown by Lindo in the novel. On her forced wedding day, she tries to think critically and be optimistic as indicated in her words, "I had on a beautiful red dress, but what I saw was even more valuable. I was strong. I was pure. I had genuine thoughts inside that no one could see, that no one could ever take away from me. I was like a wind," (Tan, 1990: 58). She knows that her future is not as she expects because as she has to marry someone whom she does not love. However, she keeps thinking positive and believing that she is strong and able to defense herself so nobody can make her down. It shows how Lindo thinks critically towards her situation and does not give up on the situation. Thinking critically belongs to breaking the silence generally as stated by Heng-Feng (2007 cited in Tangapiwut, 1990).

Lindo also shows critical thinking when her parents in law take off all the jewelry from her body because they blame her for the inability for having child. After all the jewelry was removed, she was become more optimistic instead of being down. Lindo says, "Because after the gold was removed from my body, I felt lighter, more free. They say this is what happens if you lack metal. You begin to think as an independent person," (Tan, 1990: 63). The situation triggers her to think that she is an independent woman even though she lives with no freedom in her forced marriage.

Similarly, Suyuan also shows breaking the silence in general sense when she narrates, "...We all had our miseries. But to despair was to wish back for something already lost. Or to prolong what was already unbearable... What was worse, we asked among ourselves, to sit and wait for our own deaths with proper somber faces? Or to choose our own happiness? (Tan, 1990: 24-25). Suyuan has a deep thought of women stereotypes as well as oppressions that they get from their society. She tries to break the silence by thinking critically about the stereotypes and the oppressions happened to them whether they will just accept it or the fight for their happiness. She hopes that other people will notice their presence by creating the club.

Secondly, breaking the silence is also done internally by Suyuan in the novel. She says, "...And then we would talk into the night until the morning, saying stories about good times in the past and good times yet to come..." (Tan, 1990: 24). This quotation is when Suyuan tells her daughter named Jing-Mei about her past in China. When she was in China, she and her friends share stories until the morning come. By talking to each other, sharing their stories and advising each other, they raised their knowledge about the society. It is aligned with what He-feng (2007 quoted in Tangapiwut, 2012) called as breaking the silence internally where the women try to increase their knowledge and understanding about the society.

Thirdly, externally breaking the silence is done by changing the social condition in the contemporary world by moving to another place which has developed feminist movement, civil right, and multiculturalism (He-Feng 2007 quoted in Tangapiwut, 2012). The first generation Chinese immigrant women do this struggle to face the negative stereotypes. For example, Suyuan shows her willingness to move to another place when she says, "And that's when I thought I needed something to do to help me move," (Tan, 1990: 23). Suyuan's words indicate that she wants to move to another place to help her get better life without oppressions. She finally moves to America. Jing-mei remembers that "America was where all my mother's hopes lay. She had come here in 1949 after 
losing everything in China:...But she never looked back with regret. There were so many ways for things to get better," (Tan, 1990: 132). Jing-mei explains that her mother moves to America with many hopes for getting betterment. She believes that America will give her better life, freedom, and no oppression. It is aligned to Chang (2003) who states that the typical Chinese wife had more power in the power in the United States than she could have achieved in her home village, also their children enjoy more rights in America. Similarly, He-feng (2007 quoted in Tangapiwut, 2012) also asserts that women who lived tragic life in China have become self-directed women in the United States, where they have learned to rely on and trust only themselves.

Lindo also experiences that moving to America makes her life better. She says, "It was not like my first marriage, where everything was arranged. I had a choice. I could choose to marry your father, or I could choose not to marry him.." (Tan, 1990: 66). When she is in Amerika, she has freedom for deciding what to do and what not to do in her life. One of the cases is when she is going to marry her second husband. She is not forced to marry, but she chooses to marry his husband. In America, Lindo feels that she gets her freedom.

\section{Storytelling}

Gallego (1999) argues that women who get negative stereotypes can do storytelling to end the stereotypes. He states that storytelling makes a woman and her generation break away from the negative effects of women stereotypes. In the novel, all of the first generation of Chinese immigrant women do storytelling. The first is Ying-ying who tells her daughter to be stronger as her daughter's husband always oppresses her and stereotypes her as weak and passive. The followings are the way Ying-ying makes her daughter namely Lena strong.

Now I must tell my daughter everything. That she is the daughter of a ghost. She has no chi. This is my greatest shame. How can I leave this world without leaving her my spirit? So this is what I will do. I will gather together my past and look. I will see a thing that has already happened. The pain that cut my spirit loose. I will hold that pain in my hand until it becomes hard and shiny, more clear. And then my fierceness can come back, my golden side, my black side. I will use this sharp pain to penetrate my daughter's tough skin and cut her tiger spirit loose. She will fight me, because this is the nature of two tigers. But I will win and give her my spirit, because this is the way a mother loves her daughter (Tan, 1990: 252).

The monologue above indicates that Ying-ying also experiences the negative stereotypes that make her suffered and lost her spirit. However, she tries to fight the stereotypes and wants her daughter to do the same things. By telling her story to her daughter, she demands her daughter to fight the stereotypes she gets from her husband. She cannot let her daughter being oppressed and suffered caused by the stereotypes. Finally, at the end of the story because of her mother's story, Lena is brave to say to her husband, "I just think we have to change things..." (Tan, 1990: 164). Lena shows that she speaks out her thoughts and does not accept the stereotypes given by her husband as weak and passive. Thus, she thinks that she and her husband should change the situation of their marriage.

Lindo also does storytelling to her daughter named Waverly. First is when she shares her struggle in forced marriage and how happy she is when she finally has a freedom to choose whether she wants to marry or not her second husband. Second is when she tells her daughter to have a better life than hers. She says, "...I wanted everything for you to be better. I wanted you to have the best circumstances, the best character. I didn't want you to regret anything...” (Tan, 1990: 265). From her words, she tells her daughter that the negative stereotypes bring negative effects to her life. Thus, she wants her daughter to be brave and fight the stereotypes so she will have a better life than hers.

Not to mention, An-mei also tells her daughter named Rose as the second generation stereotyped as passive in American society. Rose's husband always makes decisions for their marriage life, even worse her husband asks her for divorce because he thinks that she is too passive. 
Looking at her daughter's life, she really wants her daughter for not experiencing the same thing and being active to fight her husband. It is shown by Rose's words in the following quotation.

My mother once told me why I was so confused all the time. She said I was without wood. Born without wood so that I listened to too many people. She knew this, because once she had almost become this way. "A girl is like a young tree," she said. "You must stand tall and listen to your mother standing next to you. That is the only way to grow strong and straight. But if you bend to listen to other people, you will grow crooked and weak. You will fall to the ground with the first strong wind. And then you will be like a weed, growing wild in any direction, running along the ground until someone pulls you out and throws you away." (Tan, 1990: 191)

In the above quotation, Rose shares that her mother ever told her to be strong as a girl even though she realizes that Rose will face the same stereotypes like her. However, Rose is still passive and just lies in bed for many days, An-mei then does another storytelling as shown in this quotation; "She was quiet for a while. 'Why do you not speak up for yourself?' She finally said in her pained voice. 'Why can you talk to your husband?'...'I am not telling you to save your marriage,' she protested. 'I only say you should speak up." (Tan, 1990: 193). An-mei's words show that she demands her daughter to be active and speak up her opinions and feelings to her husband. Rose finally follows her advices, she says to her husband; "You can't just pull me out of your life and throw me away," (Tan, 1990: 196). Rose speaks up her feelings to her husband. She shows how she suffers from the marriage. From the situation, An-mei and her daughter are able to achieve reconciliation in order to make her daughter successful in facing the women stereotypes.

The last woman who does storytelling is Suyuan to Jing-mei. Jing-mei recalls about her mother and says, "And as she began to roll with one sweeping rhythm, she would start her story. Over the years, she told me the same story, except for the ending, which grew darker, casting long shadows into her life, and eventually into mine," (Tan, 1990: 21). Jing-mei remembers that her mother always tells her about the negative stereotypes that she faces and how these stereotypes brings misery to her life. Suyuan tries to give Jing-mei understanding that she has to fight the stereotypes and does not only accept the stereotypes that people give because giving up only brings more sadness in their life. Jing-mei acknowledges that her mother's stories influence her and make her strong.

In addition, Ying-ying also acknowledges Suyuan's effort to strengthen her daughter as indicated in the following statement, "Tell them the stories she told you, lessons she taught, what you know about her mind that has become your mind..." (Tan, 1990: 40). This dialogue happens between Ying-ying and Jing-mei when Jing-mei wants to meet her twin daughters in China but she does not know what to say to them. Then, Ying-ying suggests her to share the stories that Suyuan always told her and have influenced her ways of thinking and life. In can be concluded that Ying-ying expresses that Suyuan has successfully embedded in Jing-mei's mind. This situation also depicts reconciliation so the harmfulness of the negative stereotypes can be prevented as stated by Gallego (1990).

In brief, based on the explanation above, the first generation of Chinese immigrant women in the novel deal with the negative stereotypes by being active, breaking the silence, and storytelling. By doing these three struggles, they can reach their happiness, freedom, and betterment in their lives.

\section{Conclusion}

This paper finds that in dealing with the negative stereotypes, the first generation of Chinese immigrant women in The Joy Luck Club novel do their struggles in three ways including being active, breaking the silence, and storytelling. In being active, they play active role in the society. Related to breaking the silence, they do it generally, internally, and externally. In storytelling, they share their knowledge and experiences to their generation in order to fight the negative stereotypes. By doing those struggles, they successfully face the negative stereotypes. 


\section{References:}

[1] Brannon. (n.d), Gender stereotypes: Masculinity and femininity.

[2] Dovidio, J.F, Hewstone \& Glick. (n.d). Prejudice, stereotyping and discrimination: Theoretical and empirical overview, 3-28.

[3] Fajar, M., An analysis on women stereotype on the first generation of Chinese immigrant women as reflected in The Joy Luck Club Novel. Unpublished Final Project. Universitas Islam Sultan Agung,(2018)

[4] Gallego, M., Female identitiy and storytelling in Louise Erdrich's tracks and Amy Tan The Joy Luck Club. Philologia Hispalensi,(1999),131-137.

[5] Lee, J. F. K., Chinese proverbs: How are women and men represented? Multidisciplinary, Journal of Gender Studies,(2015), 559-585.

[6] Patton, M. Q. \& Cochran, M., A guide to using qualitative research methodhology. Medecins Sans Frontieres,(2002)..

[7] Peng, X., Orientalism, Chinese mother as other under patriarchy and racism: The Chinese mother's image in The Joy Luck Club from the perpective of orientalism, European Journal of Business and Social Sciences, (2014),147-156. Print.

[8] Rhim, S. M. (n.d), The status of women in China: Yesterday and today, 1-44.

[9] Snyder, R. C., What is third-wave feminism? A new directions essay, Journal of Women in Culture and Society,34(1)(2008), 175-196, https://doi.org/10.1086/588436

[10] Tan, A, The Joy Luck Club. Minerva, London(1990).

[11] Tangapiwut, N., Women's fate and faith as told in Amy Tan's The Joy Luck Club, Journal of Humanities Regular, (2012),35-49 